\title{
The Risk Factors Anesthesiologists should Pay Attention for Massive Bleeding in Placenta Accreta Spectrum Patients with Placenta Previa During Surgery: A Retrospective Study
}

\section{Fusen Huang ( $\Delta 793736612 @ q q . c o m)$}

the First Affiliated Hospital of Chongqing Medical University

Jingjie Wang

the First Affiliated Hospital of Chongqing Medical University

Jia Zhuo

the First Affiliated Hospital of Chongqing Medical University

Qiuju Xiong

the First Affiliated Hospital of Chongqing Medical University

\section{Wenjian Wang}

the First Affiliated Hospital of Chongqing Medical University

YiXu

the First Affiliated Hospital of Chongqing Medical University

Qiuling Xia

the First Affiliated Hospital of Chongqing Medical University

Xiaojuan Yang

the First Affiliated Hospital of Chongqing Medical University

\section{Research Article}

Keywords: massive bleeding, cesarean section, aortic balloon occlusion, Placenta accreta spectrum, placenta previa.

Posted Date: July 9th, 2021

DOl: https://doi.org/10.21203/rs.3.rs-644126/v1

License: (9) (1) This work is licensed under a Creative Commons Attribution 4.0 International License. Read Full License 


\section{Abstract}

Objectives: PAS combined with placenta previa exists as a high-risk factor for postpartum hemorrhage. The risk factors for predicting a certain disease may be different from the risk factors for massive bleeding during surgery for the disease. To explore whether the risk factors of massive bleeding in patients with Placenta accreta spectrum (PAS) with placenta previa underwent Cesarean section under the background of abdominal aortic balloon occlusion will be changed.

Methods: We reviewed 267 singleton pregnancies with PAS and placenta previa. Maternal history, antenatal ultrasound findings of the placenta, placement of the abdominal aortic balloon were reviewed retrospectively, and their association with massive bleeding during Cesarean section was analyzed.

Results: Multivariate Logistic regression analysis revealed that the number of pregnancies (odds ratio (OR), 2.680; 95\% Cl, 1.244-5.774), placenta location (anterior position) (OR, 3.172; 95\% Cl, 1.349-7.458) and cervical length (OR, 0.918; $95 \% \mathrm{Cl}, 0.854-0.987)$, implant area (OR, 1.018; 95\% $\mathrm{Cl}, 1.009-1.027) \square$ abdominal aorta balloon inflation $(\mathrm{OR}, 0.278 ; 95 \% \mathrm{Cl}, 0.095-0.813)$ were associated with massive bleeding $(>1000 \mathrm{~mL})$.

Conclusions: Abdominal aorta balloon inflation may change the known risk factors for hemorrhage. The number of pregnancies, placenta location (anterior position), cervical length, implant area, abdominal aorta balloon inflation are risk factors for massive bleeding during Cesarean section in cases of PAS and placenta previa. Balloon occlusion of the abdominal aorta can indeed reduce the risk of massive bleeding.

\section{Background}

In China, with the releasing of the second-child policy, the incidence of PAS patients with placenta previa has increased[1]. Previous studies have reported that perinatal massive bleeding and adherence of the placenta are associated with placenta previa[2, 3]. During a Cesarean section, when the placenta is separated, hemorrhage that threatens the life of the mother, a large number of blood products are infused and further bleeding after the operation may occur, and some mothers may even lose the opportunity to conceive again. Bleeding associated with placenta accreta is one of the most serious types of postpartum hemorrhage and remains one of the main causes of poor maternal and perinatal outcomes worldwide[4, 5]. A timely understanding of the risk factors of intraoperative hemorrhage is helpful to the anesthesiologist's preoperative preparation and intraoperative treatment.

Studies have shown that placing an abdominal aortic balloon before surgery can reduce postpartum hemorrhage in patients with PAS and placenta previa[6, 7]. Excluding some relatively few research reports on conservative treatment[8-10], this is one of the most important treatment options for these patient at present. But it is still controversial, and it needs more prospective studies to prove [11]. Furthermore, a small number of patients still had massive bleeding after the placement of the abdominal aortic balloon. 
It does not seem to be able to completely avoid massive bleeding during the operation. The effectiveness of abdominal aortic balloon occlusion needs to be further confirmed.

Understanding of postpartum hemorrhage (PPH) risk factors in these patients will be helpful in the preoperative preparation for a Cesarean section. Previous study has shown that advanced maternal age, previous Cesarean section and presence of sponge-like findings in the cervix are risk factors for massive bleeding during Cesarean section in cases of placenta previa, regardless of whether placental adherence is present[12]. Another study showed that the risk factors for PPH were maternal age $<18$ years, a previous cesarean section, history of PPH, conception through IVF, pre-delivery anemia, stillbirth, prolonged labor, placenta previa, placental abruption, PAS and macrosomia [13]. Under different research backgrounds, the risk factors for major bleeding may change. The risk factors for predicting a certain disease may be different from the risk factors for massive bleeding during surgery for the disease. Even if we know these risk factors, we have made sufficient preoperative preparations. It is also difficult for us to predict intraoperative bleeding [14]. Some patients with PAS combined with placenta previa still have hemorrhage during the operation. The cause of intraoperative bleeding is not only related to the condition of the placenta implant itself, but also related to intraoperative interventions. With sufficient preoperative preparations and various effective hemostatic measures during the operation this year, the incidence of major bleeding has a downward trend. PAS combined with placenta previa also exists as two high-risk factors for PPH [13]. Such patients are prone to major bleeding. In these patients with a high risk of hemorrhage, are their risk factors for hemorrhage during operation the same as in previous studies? Or after the placement of the abdominal aortic balloon, will the risk factors for major bleeding change? There are few related studies. If it changes, the perioperative doctor's focus needs to be changed to reduce the incidence of intraoperative hemorrhage. This study is aimed to explore the risk factors for massive bleeding of PAS combined with placenta previa under the background of abdominal aortic balloon occlusion during surgery.

\section{Patients And Methods}

This study was approved by the Ethics Committee of the First Affiliated Hospital of Chongqing Medical University (registration number: 2021-059). We retrospectively analyzed the clinical data of PAS patients with placenta previa who underwent cesarean section from October 2018 to October 2020. The inclusion criteria were patients with PAS combined with placenta previa diagnosed by color Doppler ultrasound or magnetic resonance imaging (MRI) and were further confirmed during the operation, with a history of caesarean section, and without other obstetric diseases. In addition, patients with abnormal coagulation function, anemia, and bleeding before surgery are not included. Emergency cesarean section surgery was not included in this study. Based on the results of ultrasound or magnetic resonance examinations, combined with clinical features, obstetricians pre-place abdominal aortic balloons for patients who need to. For economic reasons or other special reasons, the patient may refuse to install an abdominal aortic balloon. In patients with a balloon, if there is no obvious bleeding during the operation, the balloon will not be inflated. Data collection was accomplished by the authors by review of medical records. 
This study was approved by the Ethics Committee of the First Affiliated Hospital of Chongqing Medical University (registration number: 2021-059). We retrospectively analyzed the clinical data of PAS patients with placenta previa who underwent cesarean section from October 2018 to October 2020. The inclusion criteria were patients with PAS combined with placenta previa diagnosed by color Doppler ultrasound or magnetic resonance imaging (MRI) and were further confirmed during the operation, with a history of caesarean section, and without other obstetric diseases. In addition, patients with abnormal coagulation function, anemia, and bleeding before surgery are not included. Emergency cesarean section surgery was not included in this study. Based on the results of ultrasound or magnetic resonance examinations, combined with clinical features, obstetricians pre-place abdominal aortic balloons for patients who need to. For economic reasons or other special reasons, the patient may refuse to install an abdominal aortic balloon. In patients with a balloon, if there is no obvious bleeding during the operation, the balloon will not be inflated. Data collection was accomplished by the authors by review of medical records.

\section{Treatment methods}

The process of Cesarean section for patients without balloon placement. $20 \mathrm{U}$ of oxytocin was injected in the myometrium. If the placenta cannot be peeled off automatically, it needs to be peeled off manually. If the placenta invaded up to one-third of the myometrial layer, we excised a section of the placenta, simultaneously ligated the bleeding vessels, and applied a $\infty$-shaped suture to the placental bed. After the placenta had separated, we examined the placental bed and the depth of myometrial invasion. Choose to use ergonovine and Hemabate according to the condition of uterine contraction. Uterine compression sutures, uterine gauze packing, uterine tamponade, uterine artery ligation, or uterine artery embolization are selected according to the blood loss on the wound. Hysterectomy was performed when the bleeding could not be controlled.

The procedure of Cesarean section for patients with abdominal aortic balloon. In the DSA operating room, the abdominal aortic balloon was placed before the Cesarean section. With the help of contrast agent, the catheter position is positioned below the renal artery. Choose an appropriate size cuff, fill the cuff with contrast agent, and record the dose of the contrast agent. After the balloon placement is complete, the patient is sent to the operating room for Cesarean section. Choose to inflate or deflate the cuff according to the bleeding during the placenta dissection. If there is no obvious bleeding, the balloon is released to restore blood supply. The wound was carefully observed. If there is heavy bleeding, inflate the balloon to block the abdominal aorta, and take the following measures: suture the bleeding area, cervix pull-up suture, uterine artery ligation (or uterine artery embolization), uterine compression sutures, uterine cavity gauze packing or balloon tamponade. The surgeon will choose gauze packing or balloon tamponade for compression according to their own habits or experience. If the bleeding cannot be controlled, a hysterectomy is performed. The abdominal aortic balloon can be blocked intermittently during the operation to determine the hemostatic effect.

\section{Investigated clinical characteristics}

The primary outcome of this study was the occurrence of postpartum massive bleeding. 
Other clinical related indicators that need to be collected: the amount of red blood cell transfusion, uterus resection, maternal ICU admission and other indicators. We also reviewed the neonatal outcome including neonatal gender and birth weight. To evaluate some of the mother's clinical characteristics, including the mother's age, body mass index, gestational age at delivery, history of cesarean section, history of curettage, and number of pregnancy.

Ultrasound-related indicators that need to be collected: ultrasound examination before surgery to determine the exact location of the placenta, and at the same time to verify the exact location of the placenta in the postoperative medical records. It also includes the placental hypervascularity, the thickness of the placenta, and the length of the cervical canal.

PAS (formerly called morbidly adherent placenta) is a broad term that includes: Placenta accreta Anchoring placental villi attach to the myometrium (rather than decidua). Placenta increta - Anchoring placental villi penetrate into the myometrium. Placenta percreta - Anchoring placental villi penetrate through the myometrium to the uterine serosa or adjacent organs. Placental hypervascularity can be divided into the following four levels, including visible blood flow, relatively rich blood flow, rich blood flow and extremely rich blood flow. The position of the placenta is mainly divided into the following three situations. First, if the placenta mainly covers the anterior wall of the uterus, it is called an anterior position. Second, if the main position of the placenta is anterior and posterior, the position of the placenta is anterior and posterior. Third, if the location of the placenta is mainly in the posterior wall of the uterus, the location of the placenta is posterior.

\section{Statistical analysis}

All statistical analyses were conducted using the SPSS 22.0 software (IBM, Armonk, NY, USA). The categorical data were expressed as number/proportion and analyzed by $\mathrm{x} 2$-test, Fisher's exact test. The continuous variables were expressed as mean $\pm S D$ and analyzed by t-test. $P<0.05$ was considered statistically significant.

The association between the ultrasound and clinical characteristics and postpartum massive bleeding was analyzed by univariable and multivariable logistic regression analysis. Univariate and multivariable logistic regression analyses were used to test the association between massive bleeding and maternal age, degree of previa, history of abortion, gestational age at delivery, cervical canal length, placenta thickness, placental implant area, placental hypervascularity, and inflation of the abdominal aortic balloon.

\section{Results}

During the study period, 267 eligible women with PAS and placenta previa were identified. Among them, 87 patients were identified as massive bleeding. The patient flow chart is shown in Fig. 1. 
Characteristics of the entire cohort are presented in Table 1 for women who underwent cesarean section having massive bleeding and those who did not. 
Table 1

Clinical characteristics of the study population

\begin{tabular}{|c|c|c|c|c|}
\hline Characteristic & Total $(n=267)$ & $\begin{array}{l}\text { Non-massive } \\
\text { bleeding ( } \mathrm{n}= \\
180)\end{array}$ & $\begin{array}{l}\text { Massive } \\
\text { bleeding ( } n=87\end{array}$ & $\begin{array}{l}\mathrm{P} \text { - } \\
\text { value }\end{array}$ \\
\hline Maternal age (years), mean \pm SD & $32.68 \pm 4.21$ & $32.48 \pm 4.24$ & $33.08 \pm 4.12$ & 0.278 \\
\hline $\mathrm{BMI}$, mean $\pm \mathrm{SD}$ & $27.44 \pm 3.14$ & $27.30 \pm 2.94$ & $27.74 \pm 3.54$ & 0.282 \\
\hline Pregnancy times(n) & $3.90 \pm 1.74$ & $3.71 \pm 1.64$ & $4.30 \pm 1.88$ & 0.009 \\
\hline $\begin{array}{l}\text { Previous times of Cesarean } \\
\text { section( } \mathrm{n})\end{array}$ & $0.92 \pm 0.65$ & $0.84 \pm 0.61$ & $1.09 \pm 0.71$ & 0.003 \\
\hline $\begin{array}{l}\text { Number of prior uterine } \\
\text { curettages, }\end{array}$ & $1.79 \pm 1.56$ & $1.71 \pm 1.51$ & $1.97 \pm 1.64$ & 0.201 \\
\hline \multicolumn{5}{|l|}{ mean \pm SD } \\
\hline Gestational age & $36.40 \pm 1.48$ & $36.54 \pm 1.36$ & $36.11 \pm 1.67$ & 0.027 \\
\hline Diabetes, n (\%) & $70(26.2)$ & $51(28.3)$ & $19(21.8)$ & 0.258 \\
\hline Placenta position & & & & 0.000 \\
\hline Posterior, n (\%) & $110(41.2)$ & $93(51.7)$ & $17(19.5)$ & \\
\hline Anteroposterior, n (\%) & $90(33.7)$ & $43(23.9)$ & $47(54.0)$ & \\
\hline Anterior, n (\%) & $67(25.1)$ & $44(24.4)$ & $23(26.4)$ & \\
\hline Implant depth & & & & 0.000 \\
\hline Mucosal layer, n (\%) & $36(13.5)$ & $35(19.4)$ & $1(1.1)$ & \\
\hline Myometrium, n (\%) & $189(70.8)$ & $134(74.4)$ & $55(63.2)$ & \\
\hline Beyond myometrium, n (\%) & $42(15.7)$ & $11(6.1)$ & $31(35.6)$ & \\
\hline Implantation area $\left(\mathrm{cm}^{2}\right)$ & $68.57 \pm 44.10$ & $54.12 \pm 34.43$ & $98.46 \pm 46.98$ & 0.000 \\
\hline Placenta thickness (mm) & $42.34 \pm 8.71$ & $40.84 \pm 7.19$ & $45.44 \pm 10.60$ & 0.000 \\
\hline Hypervascularity & & & & 0.000 \\
\hline Visible, n (\%) & $89(33.3)$ & $77(42.8)$ & $12(13.8)$ & \\
\hline Relatively rich, $\mathrm{n}(\%)$ & 107(40.1) & $73(40.6)$ & $34(39.1)$ & \\
\hline Rich, n (\%) & $53(19.9)$ & $26(14.4)$ & $27(31.0)$ & \\
\hline Extremely rich, $\mathrm{n}(\%)$ & 18(6.7) & $4(2.2)$ & $14(16.1)$ & \\
\hline
\end{tabular}




\begin{tabular}{|c|c|c|c|c|}
\hline Characteristic & Total $(n=267)$ & $\begin{array}{l}\text { Non-massive } \\
\text { bleeding }(\mathrm{n}= \\
180)\end{array}$ & $\begin{array}{l}\text { Massive } \\
\text { bleeding ( } n=87\end{array}$ & $\begin{array}{l}\mathrm{P} \text { - } \\
\text { value }\end{array}$ \\
\hline $\begin{array}{l}\text { Cervical length just before } \\
\text { delivery } \\
\text { (mm), mean } \pm S D\end{array}$ & $32.51 \pm 5.16$ & $35.53 \pm 4.86$ & $30.38 \pm 5.15$ & 0.000 \\
\hline Balloon occlusion, $\mathrm{n}(\%)$ & $136(50.9)$ & $76(42.2)$ & $60(69.0)$ & 0.000 \\
\hline Neonatal weight (g) & $\begin{array}{l}2899.34 \pm \\
445.75\end{array}$ & $\begin{array}{l}2905.21 \pm \\
405.66\end{array}$ & $\begin{array}{l}2887.18 \pm \\
521.37\end{array}$ & 0.757 \\
\hline Neonatal gender & & & & 0.607 \\
\hline $\mathrm{M}, \mathrm{n}(\%)$ & $138(51.7)$ & $95(52.8)$ & $43(49.4)$ & \\
\hline $\mathrm{F}, \mathrm{n}(\%)$ & $129(48.3)$ & $85(47.2)$ & $44(50.6)$ & \\
\hline $\begin{array}{l}\text { Estimated blood loss }(\mathrm{mL}) \text {, mean } \\
\pm \mathrm{SD}\end{array}$ & $\begin{array}{l}991.24 \pm \\
1184.71\end{array}$ & $541.72 \pm 189.29$ & $\begin{array}{l}1921.26 \pm \\
1722.98\end{array}$ & 0.000 \\
\hline $\mathrm{RBC}$ transfused $(\mathrm{ml})$, mean $\pm \mathrm{SD}$ & $\begin{array}{l}208.13 \pm \\
478.01\end{array}$ & $37.50 \pm 145.69$ & $561.15 \pm 689.60$ & 0.000 \\
\hline Hysterectomy, n (\%) & $10(3.7)$ & $0(0.0)$ & $10(11.5)$ & 0.000 \\
\hline Maternal ICU admission, n (\%) & $10(3.7)$ & $1(0.6)$ & $9(10.3)$ & 0.000 \\
\hline
\end{tabular}

Univariate Logistic regression analyses for massive bleeding within 24 hours of Cesarean section in Table 2. Factors related to massive bleeding include gestational age, pregnancy times, number of previous cesarean sections, placental position, cervical canal length, depth of placental implantation, implantation area, blood flow between placenta and uterine wall, thickness of placenta, balloon inflation. 
Table 2

Results of Univariate Logistic Regression Analyses Testing the Association between Massive Bleeding and Clinical Characteristics

\begin{tabular}{|c|c|c|}
\hline Risk factor & OR $(95 \% \mathrm{Cl})$ & p value \\
\hline Maternal age & $1.035(0.973-1.100)$ & 0.277 \\
\hline BMI & $1.046(0.964-1.134)$ & 0.282 \\
\hline Gestational age & $0.826(0.694-0.983)$ & 0.031 \\
\hline Abdominal circumference & $0.998(0.998-1.008)$ & 0.688 \\
\hline Pregnancy times & $1.214(1.047-1.409)$ & 0.010 \\
\hline Previous times of Cesarean section & $1.832(1.216-2.761)$ & 0.004 \\
\hline Number of prior uterine curettages & $1.111(0.945-1.306)$ & 0.202 \\
\hline Diabetes & $0.707(0.387-1.292)$ & 0.259 \\
\hline Placenta position & & 0.000 \\
\hline Posterior & 1 & Reference \\
\hline Anteroposterior & $5.979(3.084-11.593)$ & 0.000 \\
\hline Anterior & $2.860(1.389-5.888)$ & 0.004 \\
\hline Cervical length & $0.882(0.834-0.934)$ & 0.000 \\
\hline Implant depth & & 0.000 \\
\hline Mucosal layer & 1 & Reference \\
\hline Myometrium & 14.366(1.920-107.472) & 0.009 \\
\hline Beyond myometrium & $98.636(12.037-808.237)$ & 0.000 \\
\hline Implantation area & $1.026(1.018-1.033)$ & 0.000 \\
\hline Hypervascularity & & 0.000 \\
\hline Visible & 1 & Reference \\
\hline Relatively rich & $2.989(1.438-6.213)$ & 0.003 \\
\hline Rich & $6.663(2.957-15.015)$ & 0.000 \\
\hline Extremely rich & $22.458(6.327-79.715)$ & 0.000 \\
\hline Placenta thickness & $1.062(1.030-1.095)$ & 0.000 \\
\hline Balloon occlusion & $3.041(1.769-5.229)$ & 0.000 \\
\hline
\end{tabular}

OR, odds ratio; $\mathrm{Cl}$, confidence interval; $\mathrm{BMI}$, body mass index; $\mathrm{M}$, male; F, female. 


\begin{tabular}{|lll|}
\hline Risk factor & OR $(95 \% \mathrm{Cl})$ & P value \\
\hline Amniotic fluid & $1.000(1.000-1.001)$ & 0.431 \\
\hline Neonatal gender & & \\
\hline M & 1 & Reference \\
\hline F & $1.144(0.685-1.909)$ & 0.607 \\
\hline Neonatal weight & $1.000(0.999-1.000)$ & 0.756 \\
\hline OR, odds ratio; $\mathrm{Cl}$, confidence interval; BMI, body mass index; $\mathrm{M}$, male; F, female. \\
\hline
\end{tabular}

Multivariate Logistic regression analyses for massive bleeding within 24 hours of Cesarean section in Table 3. Pregnancy times, placenta position, cervical canal length, placental accreta depth, placenta accretion area, and inflatable balloon were associated with massive hemorrhage. 
Table 3

Results of Multivariate Logistic Regression Analyses Testing the Association between Massive Bleeding and Clinical Characteristics

\begin{tabular}{|lll|}
\hline Risk factor & OR $(95 \%$ Cl $)$ & p value \\
\hline Pregnancy times & $2.680(1.244-5.774)$ & 0.012 \\
\hline Previous times of Cesarean section & $0.542(0.229-1.281)$ & 0.163 \\
\hline Placenta position & & 0.025 \\
\hline Posterior & 1 & Reference \\
\hline Anteroposterior & $1.599(0.619-4.135)$ & 0.333 \\
\hline Anterior & $3.172(1.349-7.458)$ & 0.008 \\
\hline Cervical length & $0.918(0.854-0.987)$ & 0.021 \\
\hline Implant depth & & 0.003 \\
\hline Mucosal layer & 1 & Reference \\
\hline Myometrium & $9.790(1.225-78.244)$ & 0.031 \\
\hline Beyond myometrium & $34.661(3.649-329.247)$ & 0.002 \\
\hline Implantation area & $1.018(1.009-1.027)$ & 0.000 \\
\hline Hypervascularity & & 0.265 \\
\hline Visible & 1 & Reference \\
\hline Relatively rich & $1.811(0.710-4.621)$ & 0.214 \\
\hline Rich & $2.971(0.993-8.891)$ & 0.051 \\
\hline Extremely rich & $2.906(0.556-15.180)$ & 0.206 \\
\hline Placenta thickness & $1.017(0.976-1.059)$ & 0.432 \\
\hline Balloon occlusion & $0.278(0.095-0.813)$ & 0.019 \\
\hline OR, odds ratio; Cl, confidence interval. & & \\
\hline
\end{tabular}

\section{Discussion}

$\mathrm{PPH}$ is still the main cause of maternal morbidity and mortality. PAS combined with placenta previa will increase maternal complications, such as antepartum hemorrhage, postpartum hemorrhage, massive blood transfusion, hysterectomy, sepsis and deep vein thrombosis of the lower extremities, and even cause death. 
A small number of studies have studied the risk factors of postpartum hemorrhage. Studies have pointed out that the prenatal diagnosis of such patients only relying on prenatal ultrasound still lacks clinical relevance[15]. Choi et al. [16]determined that the history of miscarriage, previous cesarean section and complete placenta previa are strong prenatal risk factors associated with perinatal cesarean section hysterectomy. These studies attempted to predict perinatal hemorrhage in patients with placenta previa[12, 17]. However, it is difficult to accurately estimate the blood loss during cesarean section $[14,18]$. Previous studies have shown that advanced maternal age, previous Cesarean section and presence of sponge-like findings in the cervix are risk factors for massive bleeding during Cesarean section in cases of placenta previa, regardless of whether placental adherence is present[12]. These studies only considered prenatal factors and did not consider interventions during surgery. These interventions may change risk factors. Therefore, in our study, not only the relevant features of pregnant women and the characteristics of the placenta under ultrasound were included, but also abdominal aorta balloon was included. Some studies (most models) select patients only in adhesive placenta [19]or placenta previa[12]. The risk of major bleeding in any single situation is relatively small [20], so we chose patients with PAS combined with placenta previa. At the same time, according to the definition of PPH revised by the American College of Obstetricians and Gynecologists, cumulative blood loss $\geq 1000 \mathrm{~mL}$ within 24 hours after delivery is considered to be postpartum hemorrhage[21].

Studies have shown that older women and previous cesarean delivery are associated with an increased risk of placental implantation[22-24]. Curettage is associated with an increased possibility of abnormally invasive placenta[22]. All of these studies are mainly to explore the risk factors for predicting PAS or complete placenta previa, or the risk factors for hysterectomy and massive blood transfusion. Only a few studies have discussed the risk factors of PAS combined with placenta previa during cesarean section. There was even previous study showing that there are few reliable predictors of massive blood loss in women with placenta accreta [14]. It is unclear whether these risk factors will change when the abdominal aortic balloon is used. When we limited to PAS with placenta previa patients, it is not clear whether the risk factors for major bleeding will change in recent years.

The risk factors for predicting a certain disease are not the same as the risk factors for massive bleeding during surgery. The severity of the disease does not determine the severity of bleeding. Our study found that the univariate logistic analysis of massive bleeding is related to gestational age, number of pregnancy, and the number of previous cesarean sections but, on multivariable analysis, the association with massive bleeding was only the number of pregnancies. Neither parity nor previous uterine surgery has anything to do with massive bleeding, which is consistent with Lee's research[17]. It also further shows that under the premise of intraoperative intervention, abdominal aortic balloon occlusion can be used as a key factor in predicting major bleeding. Our study did not find that postpartum hemorrhage is related to the age of pregnant women, which may be related to the age range of the pregnant women we choose was relatively narrow.

Previous studies related to placental ultrasonography have shown that uteroplacental hypervascularity is positively correlated with pathologically adherent placenta[25]. The normal hypoechoic disappearance 
between the placenta and myometrium is a high predictor of pathological adhesions of the placenta[25, 26]. Patients with placenta previa and lacunae have a higher risk of abnormal placenta implantation[2729]. Hypervascularization, loss of hypoechoic retroplacental zone, and lacunae are some of the risk factors for postpartum hemorrhage after placental dissection[12]. In our study, the location of the placenta, the length of the cervical canal, and the depth of placental implantation are related to the risk of bleeding $\geq 1000 \mathrm{ml}$ after delivery of the fetus. Our study have shown that anterior localization of the placenta is a risk factor for postpartum hemorrhage, which is consistent with Lal AK's research. [30] Regrettably, we have not collected relevant data on loss of hypoechoic retroplacental zone and lacunae. Similarly, in our study, hypervascularization did not appear as a risk factor.

It can be seen that the risk factors for predicting PAS or placenta previa, hysterectomy, mass blood transfusion, are not consistent with the massive bleeding factors for PAS combined with placenta previa. When we are specific about the disease that exists independently as a high risk factor for postpartum hemorrhage, the risk factors for massive hemorrhage have changed during cesarean section. The reasons for the change mainly consider the following two points: 1. History of miscarriage or Curettage, previous cesarean section, complete placenta previa, presence of sponge-like findings in the cervix, Hypervascularization, etc. as predictive factors and the diagnosis of PAS combined with placenta previa is collinear. They exist more as a diagnostic factor. 2. After the abdominal aortic balloon is inflated, some risk factors may change.

At present, for some patients with PAS combined with placenta previa, the abdominal aortic balloon will be selectively used to prevent hemorrhage after placenta dissection during the preoperative preparation process. There is no uniform standard for choosing the placement of the abdominal aortic balloon.

Therefore, we included whether or not the balloon is inflated as an influencing factor in our study. Intraoperative inflation of the abdominal aortic balloon can indeed reduce the incidence of hemorrhage during the operation. The inflation of abdominal aortic balloon reduces the risk of postpartum hemorrhage by about 3.6 fold. It is feasible to perform abdominal aortic balloon placement in patients with a clear diagnosis or high suspicion of PAS combined with placenta previa.

Some limitations of our study should also be noted. This study is limited by the nature of the retrospective cohort, and some deviations are inevitable. The acquisition of some clinical variables depends entirely on the review of medical records. As far as some relevant data on ultrasound are concerned, there is no data on loss of hypoechoic retroplacental zone and lacunae. Studies have shown that the position of the fetus is also one of the risk factors for postpartum hemorrhage [17]. The relevant information about the position of the fetus has not been collected and is not included in the study. In addition, there are many risk factors that affect postpartum hemorrhage, and the number of cases we included is still relatively small.

\section{Conclusions}


In conclusion, in this retrospective study, we found that intraoperative abdominal aorta balloon occlusion during cesarean hysterectomy did reducing intraoperative blood loss in women with PAS and placenta previa. A comprehensive assessment of the risk factors of massive bleeding in patients with PAS and placenta previa can enable doctors to do better preparation. In this situation, related doctors need to pay more attention on the number of pregnancies, the length of the cervical canal, the position of the placenta, the depth and extent of placental implantation.

\section{Declarations}

- Ethics approval and consent to participate

Ethical approval was sought from the Ethics Committee of the First Affiliated Hospital of Chongqing Medical University (registration number: 2021-059) $\square$ All methods were performed in accordance with the Declaration of Helsinki. The Ethics Committee of the First Affiliated Hospital of Chongqing Medical University informed that they waived the need for consent. For the medical records used in this study were obtained from previous diagnosis and treatment. The exemption of informed consent will not adversely affect the rights and health of subjects. The subjects' privacy and personal identity are protected.

- Consent for publication

Not applicable

- Availability of data and materials

The datasets used and/or analysed during the current study available from the corresponding author on reasonable request.

- Funding

The authors have no support or funding to report for the present study.

- Authors' contributions

FH: design of the study, collected the data and conducted the analysis and drafted the manuscript. WJ: designed the study and drafted the manuscript. JZ, WW, YX, XJ and QL: collected the data. WJ and QJ: carried out data analysis. All authors read and approved the final manuscript.

- Acknowledgements

Not applicable

\section{References}


1. Silver RM, Landon MB, Rouse DJ, Leveno KJ, Spong CY, Thom EA, Moawad AH, Caritis SN, Harper M, Wapner RJ, Sorokin Y, Miodovnik M, Carpenter M, Peaceman AM, O'Sullivan MJ, Sibai B, Langer O, Thorp JM, Ramin SM, Mercer BM: Maternal morbidity associated with multiple repeat cesarean deliveries. Obstetrics and gynecology 2006, 107:1226-1232.

2. Crane JM, Van den Hof, M C, Dodds L, Armson BA, Liston R: Maternal complications with placenta previa. American journal of perinatology 2000, 17:101-105.

3. Oyelese Y, Smulian JC: Placenta previa, placenta accreta, and vasa previa. Obstetrics and gynecology 2006, 107:927-941.

4. Silver RM: Abnormal Placentation: Placenta Previa, Vasa Previa, and Placenta Accreta. Obstetrics and gynecology 2015, 126:654-668.

5. Vintzileos AM, Ananth CV, Smulian JC: Using ultrasound in the clinical management of placental implantation abnormalities. American journal of obstetrics and gynecology 2015, 213:S70-7.

6. Bodner LJ, Nosher JL, Gribbin C, Siegel RL, Beale S, Scorza W: Balloon-assisted occlusion of the internal iliac arteries in patients with placenta accreta/percreta. Cardiovascular and interventional radiology 2006, 29:354-361.

7. Gulino FA, Di Guardo F, Zambrotta E, Di Gregorio LM, Miranda A, Capriglione S, Palumbo MA: Placenta accreta and balloon catheterization: the experience of a single center and an update of latest evidence of literature. Archives of gynecology and obstetrics 2018, 298:83-88.

8. Frank Wolf M, Maymon S, Shnaider O, Singer-Jordan J, Maymon R, Bornstein J, Tovbin J: Two approaches for placenta accreta spectrum: B-lynch suture versus pelvic artery endovascular balloon. The journal of maternal-fetal \& neonatal medicine: the official journal of the European Association of Perinatal Medicine, the Federation of Asia and Oceania Perinatal Societies, the International Society of Perinatal Obstetricians 2020, 33:2711-2717.

9. Elkhouly NI, Solyman AE, Anter ME, Sanad ZF, El Ghazaly AN, Ellakwa HE: A new conservative surgical approach for placenta accreta spectrum in a low-resource setting. The journal of maternalfetal \& neonatal medicine: the official journal of the European Association of Perinatal Medicine, the Federation of Asia and Oceania Perinatal Societies, the International Society of Perinatal Obstetricians 2020:1-7.

10. Barinov S, Tirskaya Y, Medyannikova I, Shamina I, Shavkun I: A new approach to fertility-preserving surgery in patients with placenta accreta. The journal of maternal-fetal \& neonatal medicine: the official journal of the European Association of Perinatal Medicine, the Federation of Asia and Oceania Perinatal Societies, the International Society of Perinatal Obstetricians 2019, 32:1449-1453.

11. Sivan E, Spira M, Achiron R, Rimon U, Golan G, Mazaki-Tovi S, Schiff E: Prophylactic pelvic artery catheterization and embolization in women with placenta accreta: can it prevent cesarean hysterectomy? American journal of perinatology 2010, 27:455-461.

12. Hasegawa J, Matsuoka R, Ichizuka K, Mimura T, Sekizawa A, Farina A, Okai T: Predisposing factors for massive hemorrhage during Cesarean section in patients with placenta previa. Ultrasound in 
obstetrics \& gynecology: the official journal of the International Society of Ultrasound in Obstetrics and Gynecology 2009, 34:80-84.

13. Liu C-N, Yu F-B, Xu Y-Z, Li J-S, Guan Z-H, Sun M-N, Liu C-A, He F, Chen D-J: Prevalence and risk factors of severe postpartum hemorrhage: a retrospective cohort study. BMC pregnancy and childbirth 2021, 21:332.

14. Wright JD, Pri-Paz S, Herzog TJ, Shah M, Bonanno C, Lewin SN, Simpson LL, Gaddipati S, Sun X, D'Alton ME, Devine P: Predictors of massive blood loss in women with placenta accreta. American journal of obstetrics and gynecology 2011, 205:38.e1-6.

15. D'Antonio F, Palacios-Jaraquemada J, Timor-Trisch I, Cali G: Placenta accreta spectrum disorders: Prenatal diagnosis still lacks clinical correlation. Acta obstetricia et gynecologica Scandinavica 2018, 97:773-775.

16. Choi S-J, Song SE, Jung K-L, Oh S-Y, Kim J-H, Roh C-R: Antepartum risk factors associated with peripartum cesarean hysterectomy in women with placenta previa. American journal of perinatology 2008, 25:37-41.

17. Lee JY, Ahn EH, Kang S, Moon MJ, Jung SH, Chang SW, Cho HY: Scoring model to predict massive post-partum bleeding in pregnancies with placenta previa: A retrospective cohort study. The journal of obstetrics and gynaecology research 2018, 44:54-60.

18. Bose P, Regan F, Paterson-Brown S: Improving the accuracy of estimated blood loss at obstetric haemorrhage using clinical reconstructions. BJOG: an international journal of obstetrics and gynaecology 2006, 113:919-924.

19. Rac MWF, Wells CE, Twickler DM, Moschos E, McIntire DD, Dashe JS: Placenta accreta and vaginal bleeding according to gestational age at delivery. Obstetrics and gynecology 2015, 125:808-813.

20. Hasegawa J, Nakamura M, Hamada S, Matsuoka R, Ichizuka K, Sekizawa A, Okai T: Prediction of hemorrhage in placenta previa. Taiwanese journal of obstetrics \& gynecology 2012, 51:3-6.

21. Practice Bulletin No. 183: Postpartum Hemorrhage. Obstetrics and gynecology 2017, 130:e168-e186.

22. Baldwin HJ, Patterson JA, Nippita TA, Torvaldsen S, Ibiebele I, Simpson JM, Ford JB: Antecedents of Abnormally Invasive Placenta in Primiparous Women: Risk Associated With Gynecologic Procedures. Obstetrics and gynecology 2018, 131:227-233.

23. Farquhar CM, Li Z, Lensen S, McLintock C, Pollock W, Peek MJ, Ellwood D, Knight M, Homer CS, Vaughan G, Wang A, Sullivan E: Incidence, risk factors and perinatal outcomes for placenta accreta in Australia and New Zealand: a case-control study. BMJ open 2017, 7:e017713.

24. Getahun D, Oyelese Y, Salihu HM, Ananth CV: Previous cesarean delivery and risks of placenta previa and placental abruption. Obstetrics and gynecology 2006, 107:771-778.

25. Marsoosi V, Ghotbizadeh F, Hashemi N, Molaei B: Development of a scoring system for prediction of placenta accreta and determine the accuracy of its results. The journal of maternal-fetal \& neonatal medicine: the official journal of the European Association of Perinatal Medicine, the Federation of Asia and Oceania Perinatal Societies, the International Society of Perinatal Obstetricians 2020, 33:1824-1830. 
26. Tovbin J, Melcer Y, Shor S, Pekar-Zlotin M, Mendlovic S, Svirsky R, Maymon R: Prediction of morbidly adherent placenta using a scoring system. Ultrasound in obstetrics \& gynecology: the official journal of the International Society of Ultrasound in Obstetrics and Gynecology 2016, 48:504-510.

27. Comstock CH, Love JJ, JR, Bronsteen RA, Lee W, Vettraino IM, Huang RR, Lorenz RP: Sonographic detection of placenta accreta in the second and third trimesters of pregnancy. American journal of obstetrics and gynecology 2004, 190:1135-1140.

28. Guy GP, Peisner DB, Timor-Tritsch IE: Ultrasonographic evaluation of uteroplacental blood flow patterns of abnormally located and adherent placentas. American journal of obstetrics and gynecology 1990, 163:723-727.

29. Hamada S, Hasegawa J, Nakamura M, Matsuoka R, Ichizuka K, Sekizawa A, Okai T: Ultrasonographic findings of placenta lacunae and a lack of a clear zone in cases with placenta previa and normal placenta. Prenatal diagnosis 2011, 31:1062-1065.

30. Lal AK, Hibbard JU: Placenta previa: an outcome-based cohort study in a contemporary obstetric population. Archives of gynecology and obstetrics 2015, 292:299-305.

Registration number. ChicTR2100044798

\section{Figures}




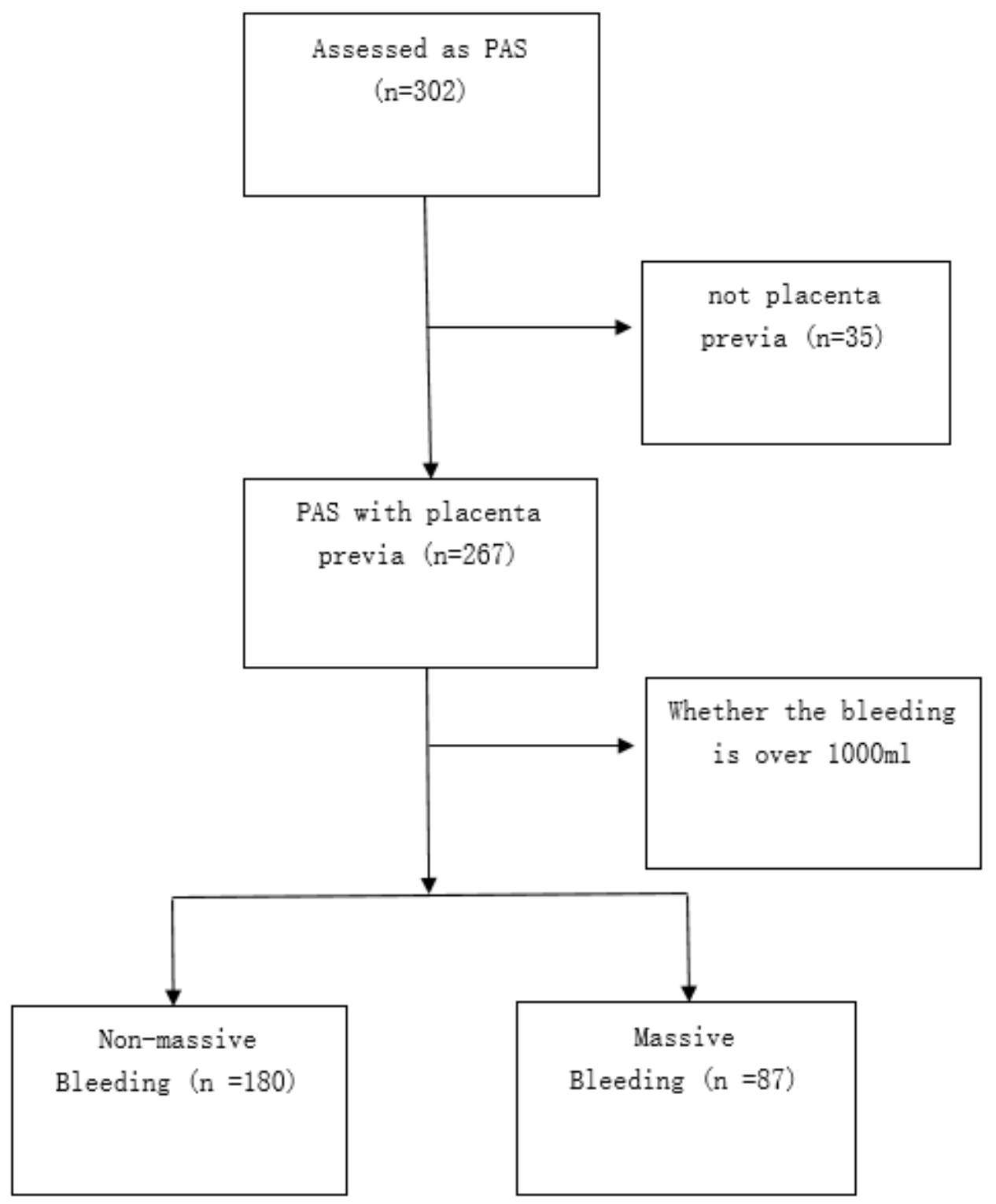

Figure 1

Flow of participants through the study. 